\title{
Pregnancy outcomes in Benghazi, Libya, before and during the armed conflict in 2011
}

\author{
Z. Bodalal, ${ }^{1}$ K. Agnaeber, ${ }^{2}$ N. Nagelkerke, ${ }^{3}$ B. Stirling, ${ }^{4}$ M. Temmerman ${ }^{5}$ and O. Degomme ${ }^{6}$
}

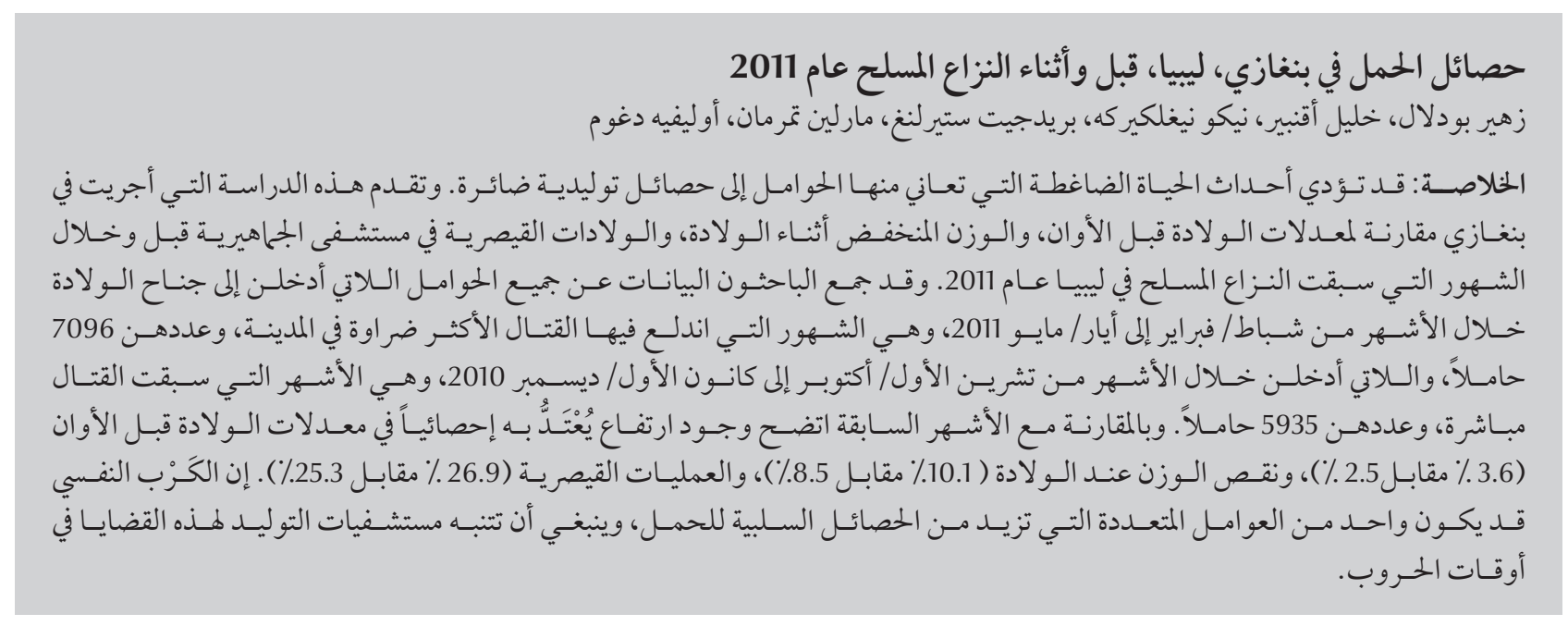

ABSTRACT Stressful life events experienced by pregnant women may lead to adverse obstetric outcomes. This study in Benghazi compared the rates of preterm, low-birth-weight and caesarean-section births at Al-Jamhouria hospital in the months before and during the armed conflict in Libya in 2011. Data were collected on all women admitted to the delivery ward during February to May 2011 (the months of the most active fighting in the city) ( $n$ = 7096), and October to December 2010 (the months immediately before the war) $(n=5935)$. Compared with the preceding months there was a significant rise during the conflict in the rate of deliveries involving preterm (3.6\% versus $2.5 \%$ ) and low-birth-weight (10.1\% versus $8.5 \%$ ) infants and caesarean sections (26.9\% versus $25.3 \%$ ). Psychosocial stress may have been a factor (among others) in an increase in negative pregnancy outcomes, and obstetric hospitals should be aware of these issues in times of war.

\section{Issues des grossesses à Benghazi (Libye) avant et pendant le conflit armé de 2011}

RÉSUMÉ Les femmes enceintes qui vivent des événements stressants peuvent être plus à risque d'une issue obstétricale défavorable. L'étude menée à Benghazi a comparé les taux de prématurité, de faible poids de naissance et de césarienne à l'hôpital Al-Jamhouria dans les mois précédant et pendant le conflit armé en Libye en 2011. Les données recueillies auprès de toutes les femmes admises en salle d'accouchement entre février et mai 2011 (au plus fort des combats dans la ville) $(n=7096)$, et entre octobre et décembre 2010 (les mois précédant la guerre) $(n=5935)$. Par rapport aux mois précédents, une augmentation importante du taux d'accouchements impliquant une prématurité $(3,6 \%$ contre $2,5 \%)$ et un faible poids de naissance $(10,1 \%$ contre $8,5 \%)$ ainsi que des césariennes (26,9\% contre 25,3\%) a été observée pendant le conflit. Le stress psychosocial peut avoir été un facteur (entre autres) dans l'augmentation des issues négatives de la grossesse, et les établissements obstétricaux devraient être informés de ces problèmes en temps de guerre.

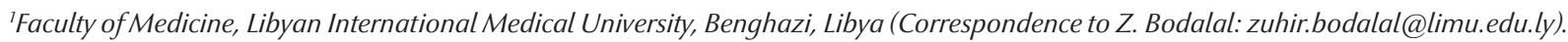
${ }^{2}$ Department of Obstetrics and Gynaecology, Al-Jamhouria Hospital, University of Benghazi, Benghazi, Libya.

${ }^{3}$ Institute of Public Health, College of Medicine and Health Sciences, United Arab Emirates University, Al Ain, United Arab Emirates.

${ }^{4}$ Island Medical Program, University of Victoria, Victoria, British Columbia, Canada.

${ }^{5}$ International Centre for Reproductive Health; ${ }^{6}$ International Centre for Reproductive Health, Department of Uro-Gynaecology Faculty of Medicine and Health Sciences, University of Ghent, Ghent, Belgium.

Received: 26/03/13; accepted: 11/07/13 


\section{Introduction}

Pregnant women have been shown to be highly vulnerable to stress [1]. Stress from major life events and other forms of emotional stress have been implicated in increasing the risk of preterm births [2-4] and low-birthweight (LBW) infants [1]. It is believed that armed conflicts aggravate social factors that increase maternal psychosocial stressors [5], and this has been significantly associated with preterm delivery $[2,6-9]$. Increases in adverse pregnancy outcomes have been recorded in many conflict and post-conflict settings such as the $\mathrm{Za}$ patista armed conflict in Mexico [10], the 11 September 2003 attacks in the United States of America [11,12] and the political/social civil unrest in Chile [13], as well as the war in Bosnia and Herzegovina [14]. Even natural disasters can increase maternal stress and increase the rate of preterm births and LBW infants [15]. Whether the adverse outcomes are related to the exposure itself (and as a corollary, the duration of exposure) $[2,3,15]$ or rather from the psychological pathologies that may have subsequently arisen [16] is not clear.

In light of the events taking place in Libya and elsewhere in the Middle East and North Africa, with major political changes accompanied by civil instability and armed conflicts, research is needed to gauge the shortand long-term health effects that these incidents induce. This study in Benghazi recorded the rates of preterm births, LBW infants and caesarean section deliveries during the period of active conflict in Libya, which ran from February to October 2011, and compared them with the months before the conflict. Data were obtained from Al-Jamhouria hospital, which admits the great majority of deliveries in this region of Libya.

\section{Methods}

\section{Sample}

A total sample consisting of 13031 deliveries were recorded for specific months before and after the conflict. Data on 7096 deliveries were collected prospectively for the 4-month period 1 February to 31 May 2011, i.e. the peak of the conflict within Benghazi. For the period immediately before the conflict, we used retrospective data on 5935 deliveries in the 3-month period 1 October to 31 December 2010. All data were collected from the labour room registry and patient records at Al-Jamhouria hospital.

Ethical approval for the study was granted by the ethics committees at Al-Jamhouria Hospital and the Libyan International Medical University.

\section{Data collection}

Data were collected on a variety of variables: maternal age, nationality, method of delivery (to measure the caesarean section rate), gestational age (to determine prematurity), birth weight (for classification purposes) and if any additional procedures were performed to the perineum (with particular emphasis on episiotomy). The procedures done to the perineum were categorized as: episiotomy, intact (where no procedure was performed) and other (consisting of tear stitches and any complications such as meconium). A preterm birth was defined as being $<37$ weeks gestation. LBW was defined as $£ 2.5 \mathrm{~kg}$. Although the World Health Organization definition of LBW is $<2.5 \mathrm{~kg}$ [17], in developing countries, heaping occurs at multiples of $500 \mathrm{~g}$ and hence almost half the infants recorded as $2.5 \mathrm{~kg}$ should be under that value [18].

\section{Data analysis}

Data were summarized as percentages and mean and standard deviation (SD). Chi-squared tests were used to compare proportions between the 2 groups. Student $t$-tests were used to compare continuous variables between the 2 periods. All statistical analyses were done using SPSS, version 18.

\section{Results}

Table 1 shows a basic comparison between the periods before and during the conflict for some key parameters. The mean age of mothers delivering in the conflict period was 30.1 (SD 5.8) years, whereas the average pre-conflict age was $30.4($ SD 5.8) years $(P<0.001)$. The proportion of foreign nationals admitted to the delivery room fell significantly from $3.2 \%$ of deliveries in pre-conflict to $1.7 \%$ during the conflict $\left(\chi^{2}=68.46, P<0.001\right)$.

From February to May 2011, there were 258 preterm births (3.6\%) out of the total 7096 births. From October to December 2010, only 150 (2.5\%) were preterm out of 5935 births. This $1 \%$ increases rate was found to be significant $\left(\chi^{2}=38.02, P<0.001\right)$. There was no statistically significant difference between the 2 periods in the age of mothers who had preterm deliveries ( $t=$ $-0.590, P=0.558)$.

Overall, the mean weight of newborns (regardless of gestational age) was significantly higher in the conflict months [3.26 (SD 0.62) kg] compared with the pre-conflict months [3.31 (SD $0.60) \mathrm{kg}](P<0.001)$. When only preterm births were compared, there was no significant difference in terms of birth weight between the 2 periods $(t=0.987$, $\mathrm{P}=0.325)$. The rate of $\mathrm{LBW}$ babies was also significantly higher (10.1\%) during the conflict period compared with $8.5 \%$ pre-conflict $\left(\chi^{2}=23.55, P<0.001\right)$.

In terms of mode of delivery, during the conflict months it was found that $1912(26.9 \%)$ of deliveries were caesarean sections, compared with 1501 deliveries (25.3\%) in 2010. There 


\begin{tabular}{|c|c|c|c|c|c|}
\hline Variable & \multicolumn{2}{|c|}{$\begin{array}{c}\text { Pre-conflict } \\
(n=5935 \text { births })\end{array}$} & \multicolumn{2}{|c|}{$\begin{array}{l}\text { During conflict } \\
\text { ( } n=7096 \text { births) }\end{array}$} & $P$-value \\
\hline Age of mother [mean $(S D)$ years] & \multicolumn{2}{|c|}{$30.4(5.8)$} & \multicolumn{2}{|c|}{$30.1(5.7)$} & $<0.001$ \\
\hline \multirow[t]{2}{*}{ Weight of baby [mean (SD) kg] } & \multicolumn{2}{|c|}{$3.31(0.60)$} & \multicolumn{2}{|c|}{$3.26(0.62)$} & $<0.001$ \\
\hline & No. & $\%$ & No & $\%$ & \\
\hline Nationality of mother & & & & & $<0.001$ \\
\hline Libyan & 5730 & 96.5 & 6976 & 98.3 & \\
\hline Foreign national & 205 & 3.5 & 120 & 1.7 & \\
\hline Maturity of baby at birth & & & & & $<0.001$ \\
\hline Full term ( $\geq 37$ weeks) & 5785 & 97.5 & 6838 & 96.4 & \\
\hline Preterm (< 37 weeks $)$ & 150 & 2.5 & 258 & 3.6 & \\
\hline Mode of delivery & & & & & 0.002 \\
\hline Caesarean section & 1501 & 25.3 & 1912 & 26.9 & \\
\hline Vaginal & 4434 & 74.7 & 5184 & 73.1 & \\
\hline Perineum & & & & & 0.006 \\
\hline Episiotomy & 2355 & 39.7 & 2949 & 41.6 & \\
\hline Intact & 1910 & 32.2 & 2205 & 31.1 & \\
\hline Other & 1670 & 28.1 & 1942 & 27.4 & \\
\hline Birth weight & & & & & $<0.01$ \\
\hline Normal $(>2.5 \mathrm{~kg})$ & 5431 & 91.5 & 6379 & 89.9 & \\
\hline Low $(\leq 2.5 . \mathrm{kg})$ & 504 & 8.5 & 717 & 10.1 & \\
\hline
\end{tabular}

${ }^{a}$ Episiotomy versus intact + other.

was a significant difference between the 2 time periods $\left(\chi^{2}=9.4, P=0.002\right)$. During the conflict, episiotomies were carried out in 2949 deliveries (41.6\%), significantly more than in 2010 (2355, $39.7 \%)\left(\chi^{2}=10.32, P=0.006\right)$.

When the daily number of premature births was plotted for the study month, there were found to be main 3 peaks, around 10 February, 16 March and 11 May 2011 (Figure 1).

\section{Discussion}

Stress during each trimester of pregnancy has been implicated in adverse outcomes. Several studies suggested that stress during the third trimester is the most harmful $[3,9,19]$, while others have implicated stress in the first [20] and second trimesters $[4,8]$ in the risk of preterm birth and LBW. Interestingly, there are a number of contradictory studies on this topic and it is clearly a point of contention despite being studied for over 3 decades [9,21].

In this study in Benghazi, the rate of preterm births and LBW infants as a proportion of total deliveries were significantly higher in the period during the armed conflict compared with the year before it started. Preterm births are a concern, as of the 15 million babies worldwide born premature each year, about 1 million will die due to complications [22]. Birth weight is commonly used as a measure of infant health [20], and LBW too may have long-term sequelae. Furthermore, a history of a LBW child puts the mother at a greater risk of preterm birth in subsequent pregnancies [23].

The recorded rate of preterm births in Al-Jamhouria hospital appears to be low when compared with international standards [24] (such as $12 \%-13 \%$ in the United States of America [25]), which is likely due to the fact that menstrual dates (rather than ultrasound) was used to establish gestational age, which fails to capture a significant proportion of preterm births [26].

While armed conflict could be a cause of this increase in adverse outcomes between the 2 study periods, confounding and selection bias could not be ruled out. For example, on average mothers during the period of the conflict were slightly, but significantly, younger than their counterparts in the pre-conflict period, which may be explained by an influx of people from neighbouring rural areas (where the average age of marriage is lower). Additionally, the fact that there were more preterm births during the conflict will automatically make the average age lower (although only by a few weeks).

Plotting the daily rate of preterm births showed 3 prominent peaks. The first 2 peaks (10 February and 16 March 2011) coincided with periods when armed forces from both sides fought directly in the city of Benghazi. The third 


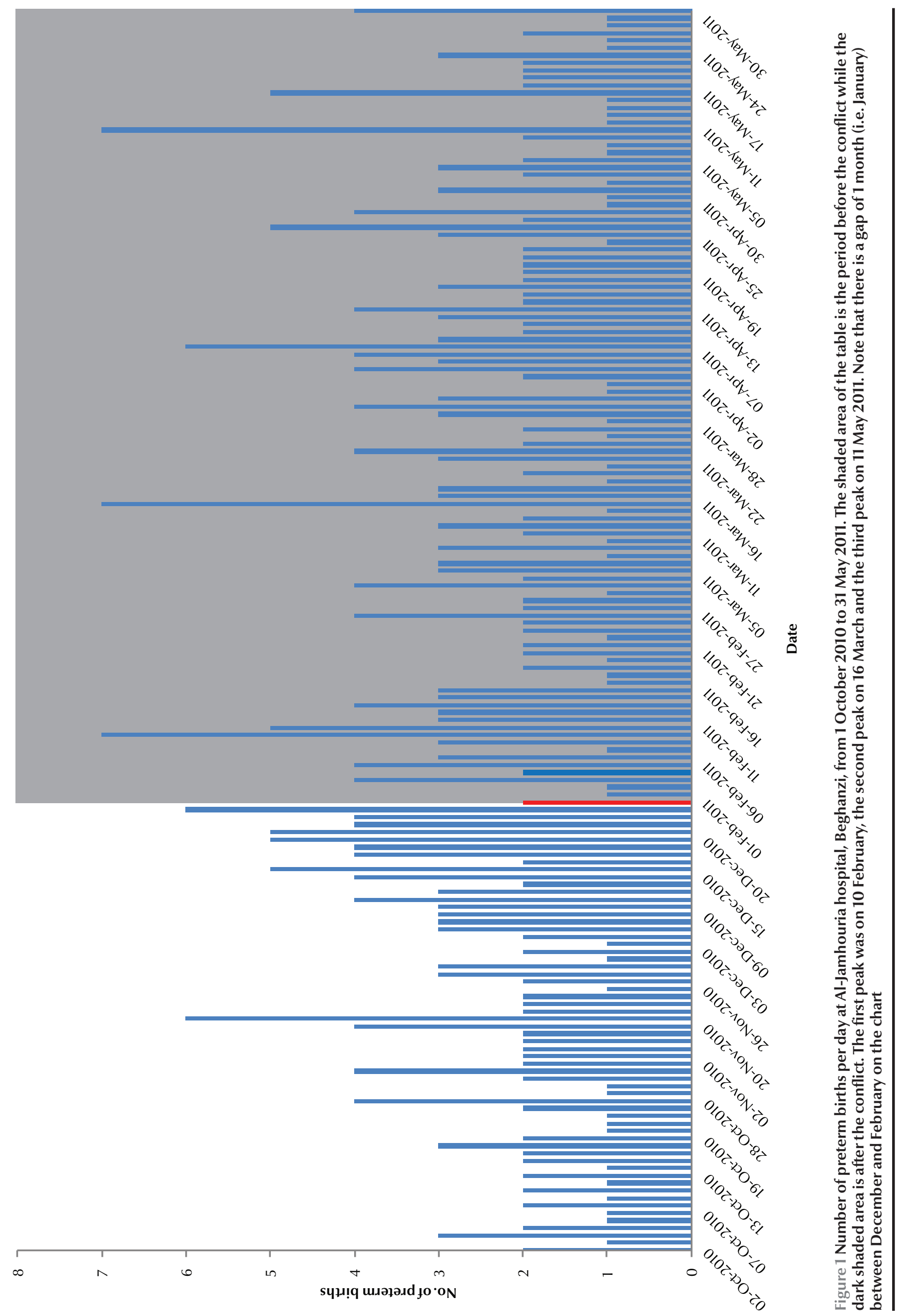


peak (11 May 2011) was around the time when there was a large influx of internally displaced people from the war-afflicted cities. The sudden onset of the conflict around 17 February 2011 must have been especially stressful to Libyan mothers who had never experienced war or armed conflict during their lifetime, although there had been some unrest in Benghazi from the beginning of February 2011 and fear that the Tunisian and Egyptian revolutions (which had started from early to mid-January) could spread to Libya.

The proportion of caesarean deliveries also increased significantly during this period, from levels that were already high by international standards (25.3\% of all deliveries), highlighting the problem faced internationally and possibly related to either a greater number of complicated cases or less experienced staff [27]. Another potential explanation could be that in times of conflict, physicians are more likely to deliver via caesarean section in order to shorten the duration of the pregnancy or labour.

The episiotomy rates also increased in the conflict months, which even prior to the conflict were extremely high compared with rates mentioned in the literature from other countries [28-31]. Such high rates may not necessarily reflect anyphysiological or biological differences, but rather poor training of obstetric teams. There was a massive loss of nursing personnel as well as midwives as a result of the conflict. Their place was taken by less experienced staff, who may well have preferred a more "convenient" episiotomy to managing difficult or protracted deliveries. Research has shown that an important factor in deciding to do an episiotomy was physician preference and not any medical need [32].

Our study thus lends more evidence to previous reports on the effect of (stress in) armed conflict on pregnancy outcomes. As the study is an interrupted time-series rather than a randomized clinical trial certain caveats seem to be appropriate. For example, data were recorded in different calendar months of 2010 and 2011 (due to data availability) and also data were not initially recorded in the files with a scientific study in mind. In particular the method of determining the prematurity of the newborn in our hospital is still largely based on estimation of gestational age.
Furthermore, conflict was used as an indirect measure of stress and no direct measures of stress were obtained.

The societal impact of conflict may be more far-reaching and long-lasting than previously thought. Pregnant women should be prioritized for protection from the effects of armed conflict, regardless of which trimester they are in. Policy-makers should be aware that conflict may result in increased negative maternal outcomes. Therefore, at times of war or civil unrest, more thought should be given to controlling the effects of LBW and prematurity in newborns. In addition more efforts should be put into place to promote feasible, costeffective care during times of conflict. Training front-line health-care workers to provide simple, evidence-based interventions will significantly reduce the effects from negative pregnancy outcomes [27].

\section{Acknowledgments}

Funding: The authors state that there were no sources of funding.

Competing interests: None declared.

\section{References}

1. Beydoun H, Saftlas AF. Physical and mental health outcomes of prenatal maternal stress in human and animal studies: a review of recent evidence. Paediatric and Perinatal Epidemiology, 2008, 22:438-466.

2. Dole $\mathrm{N}$ et al. Maternal stress and preterm birth. American Journal of Epidemiology, 2003, 157:14-24.

3. Newton RW, Hunt LP. Psychosocial stress in pregnancy and its relation to low birth weight. British Medical Journal, 1984, 288:1191-1194.

4. Abeysena C, Jayawardana P, Seneviratne RA. Effect of psychosocial stress and physical activity on preterm birth: a cohort study. Journal of Obstetrics and Gynaecology Research, 2010, 36:260-267.

5. Ahuka OL, Chabikuli N, Ogunbanjo GA. The effects of armed conflict on pregnancy outcomes in the Congo. International Journal of Gynaecology and Obstetrics, 2004, 84:91-92.

6. Copper RL et al.; National Institute of Child Health and Human Development Maternal-Fetal Medicine Units Network. The preterm prediction study: maternal stress is associated with spontaneous preterm birth at less than thirty-five weeks' gestation. American Journal of Obstetrics and Gynecology, 1996, 175:1286-1292.
7. Hedegaard M et al. Do stressful life events affect duration of gestation and risk of preterm delivery? Epidemiology, 1996, 7:339-345.

8. Nordentoft $\mathrm{M}$ et al. Intrauterine growth retardation and premature delivery: the influence of maternal smoking and psychosocial factors. American Journal of Public Health, 1996, 86:347-354.

9. Newton RW et al. Psychosocial stress in pregnancy and its relation to the onset of premature labour. British Medical Journal, 1979, 2:411-413.

10. Brentlinger PE et al. Pregnancy outcomes, site of delivery, and community schisms in regions affected by the armed conflict in Chiapas, Mexico. Social Science and Medicine, 2005, 61:1001-1014.

11. Lauderdale DS. Birth outcomes for Arabic-named women in California before and after September 11. Demography, 2006, 43:185-201.

12. Eskenazi B et al. Low birthweight in New York city and upstate New York following the events of September 11th. Human Reproduction (Oxford, England), 2007, 22:3013-3020.

13. McGinn T. Reproductive health of war-affected populations: what do we know? International Family Planning Perspectives, 2000, 26:174-180. 
14. Skokić F, Muratović S, Radoja G. Perinatal and maternal outcomes in Tuzla Canton during 1992-1995 war in Bosnia and Herzegovina. Croatian Medical Journal, 2006, 47:714-721.

15. Xiong $X$ et al. Exposure to Hurricane Katrina, post-traumatic stress disorder and birth outcomes. American Journal of the Medical Sciences, 2008, 336:111-115.

16. Rogal SS et al. Effects of posttraumatic stress disorder on pregnancy outcomes. Journal of Affective Disorders, 2007, 102:137-143.

17. Promoting optimal fetal development: report of a technical consultation. Geneva, World Health Organization, 2003.

18. Boerma JT et al. Data on birth weight in developing countries: can surveys help? Bulletin of the World Health Organization, 1996, 74:209-216.

19. Hedegaard $M$ et al. Psychological distress in pregnancy and preterm delivery. British Medical Journal, 1993, 307:234-239.

20. Mansour H, Rees D. The effect of prenatal stress on birth weight: evidence from the Al-Aqsa Intifada. Berlin, Institute for the Study of Labor, 2011 (IZA Discussion Paper 5535).

21. Dunkel-Schetter C. Maternal stress and preterm delivery. Prenatal and Neonatal Medicine, 1998, 3:39-42.

22. Born too soon: the global action report on pre-term birth. Geneva, World Health Organization, 2012.

23. Henriksen TB et al. Standing at work and preterm delivery. British Journal of Obstetrics and Gynaecology, 1995, 102:198-206.

24. Lumley J. Defining the problem: the epidemiology of preterm birth. British Journal of Obstetrics and Gynaecology, 2003, 110(Suppl. 20):3-7.
25. Goldenberg RL et al. Epidemiology and causes of preterm birth. Lancet, 2008, 371:75-84.

26. Mongelli M, Gardosi J. Birth weight, prematurity and accuracy of gestational age. International Journal of Gynaecology and Obstetrics, 1997, 56:251-256.

27. Gibbons $\mathrm{L}$ et al. The global numbers and costs of additionally needed and unnecessary cesarean sections performed per year: overuse as a barrier to universal coverage. Geneva, World Health Organization, 2010.

28. Argentine Episiotomy Trial Collaborative Group. Routine vs selective episiotomy: a randomised controlled trial. Lancet, 1993, 342:1517-1518.

29. Henriksen TB et al. Episiotomy and perineal lesions in spontaneous vaginal deliveries. British Journal of Obstetrics and Gynaecology, 1992, 99:950-954.

30. Blanchette H. Comparison of obstetric outcome of a primarycare access clinic staffed by certified nurse-midwives and a private practice group of obstetricians in the same community. American Journal of Obstetrics and Gynecology, 1995, 172:1864-1868.

31. Bansal RK et al. Is there a benefit to episiotomy at spontaneous vaginal delivery? A natural experiment. American Journal of Obstetrics and Gynecology, 1996, 175:897-901.

32. Weber AM, Meyn L. Episiotomy use in the United States, 1979-1997. Obstetrics and Gynecology, 2002, 100:1177-1182. 